\title{
GESTORES AMBIENTAIS DE ORGANIZAÇÕES PÚBLICAS: UMA ANÁLISE DAS COMPETÊNCIAS SOB A ÓTICA ACADÊMICA
}

\section{ENVIRONMENTAL MANAGERS IN PUBLIC ORGANIZATIONS: ANALYSIS OF SKILLS FROM THE ACADEMIC PERSPECTIVE}

\section{Wesley Ricardo de Souza Freitas}

Doutor em Administração pela Universidade Nove de Julho - UNINOVE, São Paulo, (Brasil). Professor Adjunto na Universidade Federal de Mato Grosso do Sul - UFMS, Campo Grande. E-mail: wesley.freitas@ufms.br

\section{Romero Albuquerque Maranhão}

Doutor em Administração pela Universidade Nove de Julho - UNINOVE, São Paulo, (Brasil). Analista ambiental na Marinha Do Brasil, Diretoria Geral Do Material - COGESN. E-mail: $\underline{\text { ram060973@gmail.com }}$

\section{Cláudia Terezinha Kniess}

Doutora em Ciência e Engenharia de Materiais pela Universidade Federal de Santa Catarina UFSC, Florianópolis, (Brasil). Docente e Pesquisadora da Universidade Nove de Julho UNINOVE, São Paulo, no Programa de Pós-graduação em Cidades Inteligentes e Sustentáveis. E-mail: kniesscl@gmail.com

\section{Cláudia Echevenguá Teixeira}

Doutora em Engenharia Civil e Ambiental pela Universidade de Sherbooke - Usherbrooke, (Canadá). Pesquisadora do Instituto de Pesquisas Tecnológicas - IPT, São Paulo, (Brasil). E-mail: ceteixeira10@gmail.com 


\title{
GESTORES AMBIENTAIS DE ORGANIZAÇÕES PÚBLICAS: UMA ANÁLISE DAS COMPETÊNCIAS SOB A ÓTICA ACADÊMICA
}

\section{RESUMO}

Este artigo tem como objetivo identificar quais as competências individuais e gerenciais fundamentais para a função de gestor ambiental público, na visão de pesquisadores e docentes de graduação e pós-graduação. Com uma abordagem qualitativa e a partir da opinião de treze pesquisadores especialistas na área ambiental, constatou-se que as competências dos gestores públicos em relação à gestão ambiental não diferem dos gestores privados. Os pesquisadores são claros quando afirmam que as organizações públicas devem possuir uma área responsável pelo meio ambiente e consequentemente um gestor ambiental. Contudo, esta é uma situação embrionária, pois a questão ambiental normalmente não é vista de forma estratégica pelas organizações do primeiro setor.

Palavras-chave: Gestão ambiental; Nova gestão pública; Gestão por competências.

\section{ENVIRONMENTAL MANAGERS IN PUBLIC ORGANIZATIONS: ANALYSIS OF SKILLS FROM THE ACADEMIC PERSPECTIVE}

\begin{abstract}
This article aims to identify the fundamental individual and management skills for public environmental manager position, according to the researchers' and undergraduate and graduate professors' point of view. With a qualitative approach and from the opinion of thirteen researchers experts in the environmental field, it was found that the public officials'skills in relation to environmental management do not differ from private managers'skills. The researchers are emphatic when they say that public organizations should have a department which is responsible for the environment and therefore an environmental manager. However, this is an embryonic situation because the environmental issue is usually not seen strategically by organizations of the first sector.
\end{abstract}

Keywords: Environmental management; New Public Management; Management skills. 


\section{INTRODUÇÃO}

Os atuais modelos de negócio das organizações estão contribuindo para o aumento da problemática ambiental (Hind, Wilson \& Lenssen, 2009). Todavia, para Porter e Van Der Linde (1995), para desenvolverem-se de forma sustentável, as organizações necessitam alterar seus modelos ou criar novos modelos de processos, produtos, matéria-prima, mercado e negócio, e assim, modificar suas estratégias organizacionais.

Nas organizações privadas e públicas, dentre essas estratégias se encontra a gestão ambiental, a qual se tornou uma importante ferramenta de modernização e competitividade para as organizações que estão, cada vez mais, buscando formalizar sua atuação ambiental por meio das certificações que, embora sejam de adoção não obrigatória, passam a constituir requisitos necessários para a entrada ou permanência em determinados mercados (Silveira, Lima, Magalhaes, Martins \& Magalhaes, 2006).

A gestão ambiental pode se tornar, também, um importante instrumento para as organizações em suas relações com consumidores, o público em geral, companhias de seguro, agências governamentais etc. (Nilsson, 1998 apud Corazza, 2003), exercendo um papel fundamental na prevenção dos danos ambientais (Chan \& Wong, 2006), e têm seu desempenho monitorado por diversos públicos (Hind, Wilson \& Lenssen, 2009).

De acordo com Barbieri (2004, p. 19) a gestão ambiental empresarial corresponde "as diretrizes e atividades administrativas e operacionais realizadas objetivando obter efeitos positivos sobre o meio ambiente, quer reduzindo os danos causados pelas ações humanas quer evitando que eles surjam". Não obstante, a competitividade empresarial passou a ser balizada também pelas questões ambientais, refletindo em uma gestão organizacional engajada com as questões do meio ambiente, determinando como requisito um elevado grau de competências técnicas (Sudin, 2011).

Wilkinson, Hill e Gollan (2001) destacam que os gestores terão de reconsiderar o papel atual no sentido de persuadir as organizações na implementação de práticas sustentáveis. Nesse contexto, Kleef e Roome (2007) questionam quais as capacidades e competências necessárias para efetivar o processo de mudança em prol da sustentabilidade ambiental. Além disso, Hind, Wilson e Lenssen (2009) recomendam que as pesquisas precisam avançar no sentido de identificar as competências gerenciais necessárias para uma gestão organizacional mais sustentável. 
Como corolário, Silveira et al. (2006), a partir de entrevistas com dez gestores ambientais de indústrias na região de Belo Horizonte/MG, identificaram as competências necessárias ao gestor ambiental (comunicação, criatividade, flexibilidade, iniciativa, foco no cliente, relacionamento interpessoal, capacidade de análise e negociação) e recomendaram verificar a aplicabilidade destas competências e outras que não foram identificadas para a função do gestor ambiental nas organizações.

Fernandes e Fleury (2007, p. 104) destacam que "há mais fumaça que fogo", pois não há um consenso sobre o conceito de competências na prática empresarial, devaneando sobre modelos originais até velhos modelos tayloristas mascarados.

Face a essa problematização, apresenta-se a questão de pesquisa: Quais as competências os gestores ambientais públicos necessitam para realizar ações socioambientais?

Dessa forma, esta pesquisa pretende identificar quais as competências individuais e gerenciais fundamentais para a função de gestor ambiental público, na visão de pesquisadores e docentes de graduação e pós-graduação. A inquietação sobre as competências do gestor ambiental público nasce face às pesquisas na área abordarem principalmente as competências de gestores de empresas privadas (Kleef \& Roome, 2007; Silveira et al., 2006).

A gestão pública brasileira é sustentada por um modelo burocrático, que surgiu por volta de 1930, à época considerado um projeto moderno (Ribeiro, 2002), em substituição ao modelo patrimonialista de administrar o Estado (Bresser-Pereira, 1996), a fim de moralizar e tornar eficiente administração pública. Contudo, as disfunções da burocracia conduzem a um modelo de gestão pública, muitas vezes, incompatível com o contexto atual. Logo, o caráter impessoal das regras transmite a inflexibilidade no gerenciamento (Saraiva \& Capelao, 2000).

Este artigo está estruturado em quatro partes, além desta introdução. No referencial teórico, são apresentados conceitos relacionados à gestão ambiental e gestão por competências e competências do gestor ambiental. Nos procedimentos metodológicos, destacam-se os fundamentos e a operacionalização da pesquisa. Na seção 4, apresentam-se os resultados e a discussão. Por fim, são apresentadas as considerações finais, as contribuições e as limitações da pesquisa.

\section{REFERENCIAL TEÓRICO}

Nesta seção, foram discutidos os conceitos relacionados à gestão ambiental e competências ambientais. 


\subsection{Gestão Ambiental}

O declínio da biodiversidade e perda da resistência dos recursos naturais é determinado por uma complexidade de fatores (Kleef \& Roome, 2007), ao passo o relacionamento do ser humano com o meio ambiente deve considerar a capacidade de suporte da natureza (Seiffert \& Loch, 2005).

Para Claver, Lopes, Molina \& Tari et al. (2007), os objetivos empresariais e ambientais devem ser coesos, isto é, as empresas devem apresentar modelos de gestão organizacional compatibilizando as atividades produtivas com o uso racional dos recursos naturais. Nesse sentido, a falta de sensibilidade e a resistência à mudança, além da falta de comprometimento e de recursos, prejudicam a efetividade de ações ambientais nas organizações, contudo, a eficácia das ações ambientais depende do grau de comprometimento das pessoas (Sroufe, Liebowitz, Sivasubramaniam \& Donahue, 2010).

As questões ambientais estão obrigando os gestores empresariais a repensarem os atuais padrões de gestão (Urban \& Govender; 2012), de maneira que o comprometimento com as questões ambientais depende da atitude dos gestores (González-Benito \& González-Benito, 2006), devendo apresentar capacidades e competências voltadas à sustentabilidade organizacional (Wilkinson; Hill \& Gollan, 2001).

O gestor ambiental deve apresentar conhecimento, habilidade e ter autoridade e autonomia para dispender recursos para efetivação das estratégias ambientais (Wee \& Quazi, 2005), além de estar engajado à causa, o que facilita, por exemplo, um processo de certificação ambiental (Daily \& Huang, 2001), sendo que o desempenho ambiental, é diretamente dependente da compreensão do gestor em relação às ameaças e oportunidade ambientais do contexto organizacional (Claver et al., 2007).

As empresas estão reconhecendo que estão em um sistema complexo e que precisam interagir em uma teia de relações com diferentes grupos interessados, de maneira que os gestores devem equilibrar as demandas conflitantes dos stakeholders (Hind, Wilson \& Lenssen (2009).

\subsection{Gestão por Competências e as Competências do Gestor Ambiental}

A elaboração de uma estratégia competitiva deve privilegiar uma competência na

Revista de Gestão e Secretariado-GeSec, São Paulo, v. 8, n. 1, p 101-118,jan./abr. 2017. 
qual a empresa mais se destaca, refletindo em novas competências a partir do ajustamento às condições do ambiente (Fleury \& Fleury, 2003). Competência é vista como a base da competitividade, permitindo que a empresa ofereça produtos e serviços de valor para os clientes, enquanto se adapta às novas circunstâncias impostas pela concorrência (Kleef \& Roome, 2007).

Zarifian (1999 apud Fleury \& Fleury, 2001, p. 186) apresenta as mudanças na organização do trabalho que induzem o surgimento do modelo de gestão por competências:

a) a noção de incidente, aquilo que ocorre de forma imprevista, não programada, vindo a perturbar o desenrolar normal do sistema de produção, ultrapassando a capacidade rotineira de assegurar sua autorregulação; isto implica que a competência não pode estar contida nas predefinições da tarefa; a pessoa precisa estar sempre mobilizando recursos para resolver as novas situações de trabalho;

b) comunicação: comunicar implica compreender o outro e a si mesmo; significa entrar em acordo sobre objetivos organizacionais, partilhar normas comuns para a sua gestão;

c) serviço: a noção de serviço, de atender a um cliente externo ou interno da organização precisa ser central e estar presente em todas as atividades; para tanto, a comunicação é fundamental.

Para Ruas (2005), o conceito de competências é demasiadamente utilizado na gestão empresarial moderna, ao mesmo tempo em que é controverso. Um dos conceitos apresentados por Fleury e Fleury (2001, p. 201) destaca a competência como: “um saber agir responsável e reconhecido, que implica mobilizar, integrar, transferir conhecimentos, recursos e habilidades, que agreguem valor econômico à organização e valor social ao indivíduo”.

As competências são mais que conhecimentos e atitudes (Lambrechts, Mulà, Ceulemans, Molderez \& Gaeremynck, 2013), devem ser relevantes e úteis para toda a organização e aplicáveis em todos os contextos (Rychen e Salganik, 2003 apud Lambrechts et al., 2013), podendo apresentar-se na dimensão organizacional e a dimensão individual, na qual se insere a dimensão gerencial, que são as competências relacionados aos aspectos funcionais (Ruas, 2005).

Segundo Ruas (2005, p. 49)

a noção de competência gerencial deve ser pensada como uma ação através da qual se mobilizam conhecimentos, habilidades e atitudes pessoais e profissionais a fim de cumprir com uma certa tarefa ou responsabilidade, numa determinada situação. A noção de competência, portanto, se torna efetiva através de ações que mobilizam capacidades.

Revista de Gestão e Secretariado-GeSec, São Paulo, v. 8, n. 1, p 101-118,jan./abr. 2017. 
As competências gerenciais são pautadas na performance do gestor, devendo ser concebidas sob um prisma dinâmico e flexível, contudo, não necessariamente levam às competências organizacionais (Oderich, 2001), mas devem estar em sintonia com as estratégias corporativas (Brandão \& Guimarães, 2001), consistindo no "desenvolvimento de capacidades que podem se posteriormente mobilizadas em situações em sua maioria pouco previsíveis" (Ruas, 2005, p. 9), isto é, não há competências sem ação, pois, a competência só se apresenta na aplicação (Le Boterf, 2003).

Fernandes e Fleury (2007), destacam que a competência individual é relacionada ao acúmulo de conhecimentos, habilidades e atitudes a montante, e entrega do estoque a jusante, que são desenvolvidas a partir da atuação profissional em funções de maior complexidade, relacionado às demandas organizacionais.

Hind, Wilson e Lenssen (2009) apresentaram em seu estudo o conhecimento, as habilidades e as atitudes como competências constituintes do comportamento empresarial responsável.

Vatimbella apud Corazza (2003) destaca um conjunto de competências que integram as atividades deste profissional, segundo a frequência das tarefas executadas, envolvendo: administração geral, implementação de processos, auditoria interna, gestão de riscos, segurança, sensibilização de pessoal, relações com representantes de diferentes setores da sociedade, comunicação externa, manutenção, qualidade, relações jurídicas e marketing.

Roorda (2010 apud Lambrechts et al., 2013) apresenta responsabilidade, inteligência emocional, orientação sistêmica, envolvimento pessoal, orientação para o futuro e capacidade de ação como competências indispensáveis para desenvolvimento sustentável.

Kleef e Roome (2007) identificaram as capacidades de gestão (pensamento sistêmico; capacidades para a integração das questões ambientais e sociais na perspectiva do negócio; capacidades para desenvolver modelos de negócios; capacidades de aprendizagem e desenvolvimento; redes sociais e capacidades; e aliança e a construção de capacidades de colaboração), que contribuem para o desenvolvimento de competências para a gestão de negócios sustentáveis.

Silveira et al. (2006) destacaram comunicação, criatividade, organização do trabalho, flexibilidade, iniciativa, trabalho em equipe, relacionamento interpessoal, foco no cliente, capacidade de análise, negociação, tomada de decisão, raciocínio numérico e autocontrole como competências gerenciais necessárias para a função de gestor ambiental. 
Muitas competências contribuem para a composição de um perfil do gestor ambiental, que pode ser abrangido a partir de um conjunto de habilidades que Donaire (1999 apud Corazza, 2003) reúne em quatro categorias (Quadro 1):

\begin{tabular}{|c|c|c|}
\hline \multirow{4}{*}{ Habilidades } & Técnica & $\begin{array}{l}\text { Para poder avaliar as diferentes alternativas, em relação a insumos, } \\
\text { processos e produtos, considerando-os sob o aspecto ambiental e seu } \\
\text { relacionamento com os conceitos de custos e de tempo. }\end{array}$ \\
\hline & Administrativa & $\begin{array}{l}\text { Relacionada com o desempenho das tarefas do processo administrativo: } \\
\text { planejar, organizar, dirigir e controlar, pois caberá a ele a } \\
\text { responsabilidade de executar a política de meio ambiente ditada pela } \\
\text { organização. }\end{array}$ \\
\hline & Política & $\begin{array}{l}\text { Para sensibilizar os demais administradores da empresa, que lhe podem } \\
\text { dar apoio e respaldo organizacional no engajamento da temática } \\
\text { ambiental, propagando e consolidando a ideia de que sua atividade, antes } \\
\text { de ser uma despesa a mais para a organização, é uma grande oportunidade } \\
\text { para a prospecção de novas formas de redução de custos e melhoria de } \\
\text { lucros. }\end{array}$ \\
\hline & $\begin{array}{l}\text { Relacionamento } \\
\text { humano }\end{array}$ & $\begin{array}{l}\text { Para conseguir a colaboração e o engajamento de todos os funcionários } \\
\text { para a causa ambiental da empresa, pois o sucesso desse empreendimento } \\
\text { está intimamente ligado à participação coletiva e à incorporação desta } \\
\text { variável à cultura da organização. }\end{array}$ \\
\hline
\end{tabular}

Quadro 1: Habilidades do gestor ambiental

Fonte: Adaptado de Donaire (1999 apud Corazza, 2003)

O quadro 1 apresenta as habilidades que estão associadas às competências citadas por Vatimbela apud Corazza (2003), principalmente as de relacionamento humano, bem como as mencionadas por Silveira et al. (2006). Tais habilidades são aderentes às competências requeridas pela nona administração pública.

\section{PROCEDIMENTOS METODOLÓGICOS}

Em razão do objetivo proposto, está pesquisa têm um caráter exploratório, pois busca investigar um tema com conhecimento pouco acumulado ou não sistematizado (Vergara, 2005).

Por meio de uma abordagem qualitativa, que segundo Zanelli (2002, p. 83), busca “entender o que as pessoas apreendem ao perceberem o que acontece em seus mundos". De

Revista de Gestão e Secretariado-GeSec, São Paulo, v. 8, n. 1, p 101-118,jan./abr. 2017. 
acordo com Creswell (2010, p. 43) a abordagem qualitativa é "um meio para explorar e para entender o significado que os indivíduos ou os grupos atribuem a um problema social ou humano", isto é, investigação empírica que averigua um fenômeno contemporâneo dentro de seu contexto da vida real (Yin, 2005), buscou compreender a perspectiva acadêmica sobre as competências de gestores públicos ambientais.

A estratégia utilizada para coleta das evidências foi o questionário, com cinco questões abertas. As vantagens do uso do método do questionário em relação às entrevistas são: utiliza menos pessoas para ser executado e proporciona economia de custo, tempo, viagens, com obtenção de uma amostra maior e não sofre influência do entrevistador (Marconi e Lakatos, 1996; Mattar, 1996). Os questionários foram enviados no dia 3 de julho para um total de 18 professores de graduação e pós-graduação, contudo apenas 13 retornaram com os questionários. O último questionário recebido foi no dia 6 de julho de 2013.

A unidade de análise, que é determinada pelos objetivos da pesquisa, podendo ser no nível organizacional ou individual (Voss, Tsikriktsis \& Frohlich, 2002), consistiu em 13 docentes/pesquisadores das universidades abaixo destacadas:

- quatro docentes da Universidade Nove de Julho- Uninove, em São Paulo/SP;

- três docentes da Universidade Estadual Paulista- Unesp, em Bauru/SP;

- três docentes da Universidade Federal de Mato Grosso do Sul, UFMS, de Três Lagoas/MS e Paranaíba/MS;

- um docente do Centro Universitário das Faculdades Metropolitanas Unidas, em São Paulo/SP;

- um docente da Universidade Toledo - Unitoledo, Araçatuba/SP;

- um docente da Faculdade Sul Brasil - Fasul, Toledo/PR.

Como procedimento de análise, buscou-se, inicialmente descrever os achados e comparar com o referencial teórico utilizado. Os dados foram tratados a partir da análise de conteúdo como base na conceituação de Bardin (2006). De acordo com Vergara (2005), a análise de conteúdo constitui uma técnica que trabalha os dados coletados, objetivando a identificação do que está sendo dito a respeito de determinado tema, comparando-se os resultados com a literatura utilizada como pano de fundo. 


\section{RESULTADOS E DISCUSSÃO}

Todos os respondentes foram enfáticos afirmando que a administração pública ocasiona impactos no meio ambiente. Mesmo em uma amplitude reduzida, se comparada às indústrias manufatureiras, as organizações públicas são grandes consumidoras de bens e serviços, e não obstante, ocasionam impactos, como por exemplo, excesso de papelório decorrente da burocracia, uso dos recursos naturais, como energia e água e geração de resíduos nos ambientes. Segundo um respondente, não existem organizações com impacto zero, pois todas são constituídas por pessoas, de maneira que o impacto ambiental é decorrente de uma atividade antrópica, isto é, as alterações no meio ambiente sempre irão ocorrer, sejam positivas ou negativas.

Nesse sentido, um dos respondentes destacou a importância no processo de licitação nas questões ambientais públicas:

Compete às organizações da Administração Pública, o provimento de serviços à população, realizado por empresas selecionadas através de processo licitatório. Caso os editais de chamamento não possuam itens claros relacionados à responsabilidade ambiental, a prestação de serviços realizados por essas empresas irá impactar o meio ambiente, direta ou indiretamente.

Apesar de destacarem que as organizações públicas, independentemente do tipo ocasionam impactos ambientais, não houve consenso, sendo que apenas oito respondentes consideram que as organizações públicas devem possuir uma área responsável pela gestão ambiental; entretanto, destacaram que naquelas que possuem, ainda é uma prática embrionária, o que demonstra que os objetivos organizações e ambientais nas organizações públicas podem não estar alinhados (Claver et al., 2007):

Nas prefeituras, no estado e no governo federal, facilmente você vai encontrar secretarias e ministérios que tratem do tema. Nas organizações de maior porte, prolifera a percepção de que as os negócios devem ser pensados no sentido de utilização mais racional dos recursos, bem como dos processos. Assim, é comum encontrar organizações públicas estruturando áreas ou setores para inserir a questão ambiental na sua filosofia, nos seus processos e rotinas, enfim, em uma perspectiva estratégica. Contudo, cabe destacar que esse processo ainda parece ser bem incipiente para a maior parte das organizações públicas.

E mesmo quando apresenta setor ou um responsável, as organizações públicas não são eficientes, pois não há pessoas com as competências necessárias nos cargos ambientais, 
são nomeadas por questões políticas e não por aspectos técnicos, sendo muitas vezes ineficazes, sendo poucas organizações que apresentam uma gestão ambiental pró-ativa.

Assim, nas organizações públicas que apresentam um setor responsável pela gestão ambiental, um dos respondentes afirmou que não fazem nada além do que a legislação determina; em contrapartida, apenas as organizações públicas que têm os recursos naturais como "parte do negócio" (água, energia, petróleo, saneamento etc.) apresentam uma gestão ambiental estruturada.

Sobre as competências individuais, os professores/pesquisadores pesquisados são coerentes a literatura (Corazza, 2003; Silveira et al., 2006; Donaire, 1999; Sroufre et al., 2010; Kleef; Rome, 2007; Roorda, 2010 apud Lambrechts et al., 2013), ao afirmarem as competências que o gestor ambiental deve possuir:

- $\quad$ capacidade de comunicação;

- $\quad$ capacidade de mobilização e desenvolvimento das pessoas;

- $\quad$ trabalho em equipe e relacionamento pessoal;

- $\quad$ liderança, para estimular, promover e convencer todos os funcionários públicos e as partes interessadas a inserirem a cultura ambiental em suas ações cotidianas;

- $\quad$ iniciativa, no sentido de ter atitude para enfrentar os problemas. Segundo um pesquisador, é uma competência importante e difícil de ser encontrada na esfera pública;

- comprometimento, pois gestor ambiental público precisa ser sensível às questões ambientais e sociais, para fazer além daquilo que a legislação determina, e na falta deste prejudica a eficácia das ações ambientais (Sroufe et al., 2010);

- $\quad$ administrar conflitos;

- $\quad$ ética, para agir dentro dos princípios que regem a atividade pública;

- $\quad$ ser proativo;

- resiliência, que é a capacidade de lidar com problemas: envolve uma capacidade pessoal difícil uma vez que o trabalho do gestor ambiental lida diariamente com problemas importantes relacionados ao processo produtivo e aos seus impactos. Envolve ainda, um trabalho árduo na mudança cultural de empregados, fornecedores, população etc., que demandam do gestor a capacidade de enfretamento de problemas diários;

- $\quad$ idealismo, acreditar na causa;

- visão sistêmica: compreender fenômenos complexos, especialmente a importância das questões ambientais para os negócios públicos, que devem servir como 
exemplo para as empresas privadas, além dos impactos no meio ambiente e na sociedade, considerando as várias demandas dos diversos atores sociais envolvidos; e

- $\quad$ capacidade de negociação, destacado por Silveira et al. (2006).

Sobre as competências gerenciais, os gestores ambientais de organizações públicas devem possuir o conhecimento técnico sobre a legislação e gestão ambiental, para que as práticas ambientais sejam efetivas, conhecimento dos impactos ambientais atuais e futuros, além de apresentar conhecimento de gestão organizacional, para que os recursos sejam devidamente geridos, em outras palavras, segundo Ruas et al. (2005), colocar em ação os conhecimentos e habilidades, conforme argumentos de um respondente, constituindo um comportamento empresarial responsável (Hind, Wilson \& Lenssen, 2009).

"O gestor ambiental precisa ser um bom administrador, no sentido de alocar devidamente os recursos, com base em avaliações de risco e de prioridades."

O conhecimento técnico é importante para que efetivamente compreenda a problemática ambiental e desenvolva ações adequadas com resultados efetivos, habilidade é necessária para colocar o conhecimento em prática, conforme Wee e Quazi (2005) que afirmaram que para efetivação das estratégias ambientais é imprescindível conhecimento e habilidades; e atitude para estar disposto a implementar processo de certificações, controle de qualidade e preservação ambiental, isto é, o comprometimento com a causa ambiental depende da atitude dos gestores.

Um dos respondentes destacou a questão da formação educacional na área ambiental, enfatizando que esta contribuiria para a gestão ambiental pública efetiva.

É necessário ter especialização na área, estar sempre pesquisando e conectado aos acontecimentos mundiais. No caso de pós-graduação, caso não tenha no Brasil, entendo que deva haver intercâmbio para buscar especialização no exterior, principalmente em países desenvolvidos.

Além disso, o gestor necessita de habilidades para o tratamento com as pessoas, habilidade para planejar ações a partir das demandas locais, precisa ser negociador com os demais atores sociais que compõem a rede de stakerolders, precisa ser um bom comunicador com este público, que corrobora as habilidades propostas por Donaire (1999). Ainda, as experiências individuais são importantes para adquirir bons resultados profissionais.

A questão da sustentabilidade ambiental está na pauta das organizações públicas há pouco tempo e a compreensão de conceitos e técnicas sobre meio ambiente e dos impactos ambientais gerados pela atividade pública, é uma competência gerencial básica e importante para o gestor público independentemente da organização. Muitos dos problemas e dos Revista de Gestão e Secretariado-GeSec, São Paulo, v. 8, n. 1, p 101-118,jan./abr. 2017. 
impactos ambientais são decorrentes da falta de conhecimento das questões ambientais, o que confirma as dúvidas de Kleef e Roome (2007) sobre as capacidades e competências fundamentais à mudança para a sustentabilidade ambiental.

Outra competência gerencial pública citada refere-se à orientação estratégica, na qual o gestor deve ser capaz de pensar a questão ambiental como estratégica para a organização. Trata-se de uma competência complexa de se instalar nos gestores públicos, pois nas indústrias que têm seus produtos e/ou processos diretamente ligados a impactos ambientais e, por isso, os gestores conseguem visualizar melhor a importância do tema para os resultados organizacionais, diferentemente de muitos gestores públicos de organizações que não utilizam diretamente os recursos naturais nas atividades produtivas. No entanto, inserir a questão ambiental como sendo importante em toda a cadeia não é uma competência que os gestores públicos dominem, mas é primordial para que a questão ambiental deixe de ser apenas um discurso; logo, se as organizações não repensarem seus modelos de gestão, não terão condições de contribuir para a sustentabilidade ambiental (Hind, Wilson \& Lenssen, 2009).

A competência gerencial para resultados, citada por alguns respondentes, que estabelece os resultados de longo prazo esperados para o negócio é fundamental para o desempenho dos gestores ambientais públicos, o que corresponde aos princípios de Fernandes e Fleury (2007), que destacaram que não basta apenas apresentar um acúmulo de conhecimento e habilidades, mas sim colocar em ação essas capacidades no sentido de mobilizar e atender as demandas organizacionais.

Todos consideram que a questão ambiental deve ser tratada de forma estratégica pelas organizações públicas, pois a própria natureza essencial da coisa pública implica uso eficiente dos recursos, especialmente visando atender às demandas da sociedade, devendo se apresentar como exemplos de gestão ambiental, um espelho para o restante da sociedade, pois caso contrário o setor público não conseguirá induzir melhorias no setor privado, conforme argumentos de um respondente: "não é cabível que apliquem multas para empresas e cometam as mesmas falhas".

$\mathrm{Na}$ visão de um respondente, as questões ambientais permeiam todas as atividades e processos internos de uma organização pública, inclusive as relações com seus stakerolders (fornecedores, clientes, cidadãos etc.) geram impactos ambientais em toda a cadeia que a organização participa. Sendo assim, a gestão ambiental deve integrar os objetivos estratégicos da organização e fazer parte de todas as práticas internas e externas, especialmente contribuindo para a mudança cultural de pessoas e empresas a partir de uma gestão estratégica Revista de Gestão e Secretariado-GeSec, São Paulo, v. 8, n. 1, p 101-118,jan./abr. 2017. 
sustentável, uma vez que consequências ambientais causadas em virtude do descaso com o assunto poderão afetar toda a população, conforme argumentos de um respondente:

Sem dúvida deve ser tratada como um tema estratégico e imprescindível. A gestão ambiental em países desenvolvidos na administração pública não são recentes, (sic) porém no Brasil, é visível a menos de uma década. Há muito para ser pesquisado e implementado para que possamos contribuir na redução dos impactos ambientais.

Como não estão isoladas do meio, a questão ambiental deve ser tratada como um tema estratégico em organizações públicas uma vez que envolve vários atores sociais; logo, é necessário pensar estrategicamente sobre a gestão ambiental, de maneira que as partes interessadas estejam satisfeitas e que as ações desemboquem em melhor qualidade de vida e bem comum.

Essa perspectiva da aplicação de competências ambientais para os gestores públicos está inserida no contexto da New Public Management ou nova gestão pública, que consiste na incorporação de princípios privados no modelo tradicional de gestão pública, como gestão por objetivos, busca pela eficiência e descentralização, flexibilização administrativa e foco na demanda (Ayres, 2006), em que o princípio fundamental é a defesa do interesse público (Coutinho, 2000) e aderentes às habilidades explicitadas no quadro 1.

\section{CONSIDERAÇÕES FINAIS}

Esta pesquisa teve como objetivo identificar quais as competências individuais e gerenciais fundamentais para a função de gestor ambiental público, na visão de pesquisadores e docentes de graduação e pós-graduação. Constatou-se que a professores da área de administração e engenharia de produção, que responderam o questionário, não diferem das competências dos gestores públicos dos gestores privados, citados por Roorda (2010 apud Lambrechts et al., 2013), Kleef e Roome (2007) e Silveira et al. (2006).

Nota-se que os pesquisadores são claros quando afirmam que as organizações públicas devem possuir uma área responsável pelo meio ambiente e consequentemente um gestor ambiental, contudo, esta é uma situação embrionária. Além do mais, consideram que a questão ambiental deve ser tratada como estratégica, pois questionam como podem cobrar das empresas privadas se não são exemplos de gestão. Logo, este artigo espera contribuir no sentido de explorar as competências gerenciais dos gestores ambientais públicos, pouco evidenciada na literatura e consonante ao novo modelo de gestão pública. 
Como limitações metodológicas, face ao objetivo proposto, esta pesquisa utilizou apenas um instrumento de coletas de dados, não atendendo as recomendações de autores como Yin (2005) e Eisenhardt (1989), que recomendam a triangulação. Outra limitação que se pode destacar refere-se à verificação de apenas "um lado da moeda", isto é, seria interessante replicar o questionário junto aos gestores ambientais públicos e comparar com os achados desta pesquisa.

\section{REFERÊNCIAS}

Ayres, C. B. (2006). A administração pública brasileira e as vicissitudes do paradigma de gestão gerencial. Sociologia, problemas e práticas, 51, 29-52.

Barbieri, J. C. (2004). Gestão ambiental empresarial: conceitos, modelos e instrumentos. São Paulo: Ed. Saraiva,.

Bardin, L. (2006). Análise de conteúdo. Lisboa: Edições 70.

Brandão, H. P. \& Guimaraes, T. A. (2001). Gestão de competências e gestão de desempenho: tecnologias distintas ou instrumentos de um mesmo construto? Revista de Administração de Empresa, 41(1), 8-15.

Bresser-Pereira, L. C. (1996). Da administração pública burocrática à gerencial. Revista do Serviço Público, 47(1).

Chan E. S. W. \& Wong, S. C. K. (2006). Motivations for ISO 14001 in the hotel industry. Tourism Management, 27, 481-492.

Claver, E.; Lopes, M. D.; Molina, J. F. \& Tari, J. J. (2007). Environmental management and firm performance: A case study. Journal of Environmental Management, 84(4), 606-619.

Corazza, R. I. (2003). Gestão ambiental e mudanças da estrutura organizacional. RAEeletrônica, 2(2), jul.-dez. 
Coutinho, M. J. V. (2000). Administração pública voltada para o cidadão: quadro teórico conceitual. Revista do Serviço Público. 51(3), 40-73.

Creswell, J. W. W. (2010). Projeto de pesquisa: métodos qualitativo, quantitativo e misto (2a ed.). Porto Alegre: Bookman.

Daily, B. F. \& Huang, S.C. (2001). Achieving sustainability through attention to human resource factors in environmental management. International Journal of Operations \& Production Management, 21(12), 1539-1552.

Donaire, D. (1999). Gestão ambiental na empresa (2a ed.). São Paulo: Atlas.

Eisenhardt, K. M. (1989). Building Theories from Case Study Research. The Academy of Management Review, 14 (4), 532-550.

Fernandes, B. H. R. \& Fleury, M. T. (2007). Modelo de gestão por competência: Evolução e teste de um sistema. Análise, 18(2), 103-122.

Fleury, A. C. C. \& Fleury, M. T. L. (2003). Estratégias competitivas e competências essenciais: perspectivas para a internacionalização da indústria no Brasil. Gestão e Produção, 10 (2).

Fleury, M. T. L. \& Fleury, A. (2001). Construindo o conceito de competência. Revista de Administração Contemporânea, vol. r. número especial.

González-Benito, J. \& González-Benito, O. (2006) A review of determinant factors of environmental proactivity. Business Strategy and the Environment, 15, 87-102.

Hind, P.; Wilson, A. \& Lenssen, G. (2009). Developing leaders for sustainable business. Corporate Governance, 9(1), 7-20.

Kleef, J. A. G. \& Roome, N. J. (2007). Developing capabilities and competence for sustainable business management as innovation: a research agenda. Journal of Cleaner Production, 15, 38-51.

Revista de Gestão e Secretariado-GeSec, São Paulo, v. 8, n. 1, p 101-118,jan./abr. 2017. 
Lambrechts, W.; Mulà, I.; Ceulemans, K.; Molderez, I. \& Gaeremynck, V. (2013). The integration of competences for sustainable development in higher education: an analysis of bachelor programs in management. Journal of Cleaner Production, 48, 65-73.

Le Boterf, G. (2003). Desenvolvendo a competência dos profissionais. Porto Alegre: Artmed.

Marconi, M. D. A. \& Lakatos, E. M. (1996). Técnicas de pesquisa: planejamento e execução de pesquisas, amostragens e técnicas de pesquisas, elaboração, análise e interpretação de dados (3a ed.). São Paulo: Atlas.

Mattar, F. N. (1996). Pesquisa de marketing: edição compacta. São Paulo: Atlas.

Oderich, C. L. (2001). Gestão de competências gerenciais: Noções e processos de desenvolvimento em três empresas gaúchas. Dissertação de mestrado, Universidade Federal do Rio Grande do Sul.

Porter, M. \& Van Der Linde, C. (1995). Toward a new conception of the environmentcompetitiveness relationship. Journal of Economic Perspectives, 9(4), 97-118.

Ribeiro, S. M. R. (2002). Reforma do aparelho de Estado no Brasil: uma comparação entre as propostas dos anos 60 e 90. VII Congreso Internacional del CLAD sobre la Reforma del Estado y de la Administración Pública, Lisboa, Portugal, 8-11 Out.

Ruas, R. L. (2005). Gestão por competências: uma contribuição à estratégia das empresas. In.: Ruas, R. L.; Antonello, C. S. \& Boff, L. H. (Orgs.). Os novos horizontes da gestão: aprendizagem organizacional e competências. Porto Alegre: Bookman.

Saraiva, L. A. S. \& Capelao, L. G. F. (2000). A nova administração pública e o foco no cidadão: burocracia X marketing? Revista de Administração Pública, 34(2), 59-77.

Seiffert, M. E. B. \& Loch, C. (2005) Systemic thinking in environmental management: support for sustainable development. Journal of Cleaner Production, 13 (12), 1197-1202. 
Silveira, D.; Lima, A.; Magalhaes, E.; Martins, G. \& Magalhaes, E. (2006). Competências requeridas no contexto da gestão ambiental. In.: Simpósio de Excelência em Gestão e Tecnologia, III SEGeT. Anais... Rio de Janeiro.

Sroufe, R.; Liebowitz, J.; Sivasubramaniam, N. \& Donahue, J. F. (2010). Are you a leader or a laggard? HR's role in creating a sustainability culture. People \& Strategy, 33(1), 34-42.

SUDIN, S. Strategic GHRM: A proposed model that supports Corporate Environmental Citizenship. In.: 2011 International Conference on Sociality and Economics Development IPEDR, Singapore, v. 10, 2011.

Urban, B. \& Govender, D. P. (2012). Empirical evidence on environmental management practices. Inzinerine Ekonomika-Engineering Economics, 23(2), 209-215.

Vergara, S. C. (2005). Projeto e relatórios de pesquisa em administração (6a ed.). São Paulo: Atlas.

Voss, C.; Tsikriktsis, N. \& Frohlich, M. (2002). Case research in operations management. International Journal of Operations \& Production Management, 22(2), 195-219.

Wee, Y. S. \& Quazi, H. A. (2005). Development and validation of critical factors of environmental management. Industrial Management \& Data Systems, 105(1), 96-114.

Wilkinson, A. Hill, M. \& Gollan, P. (2001). The sustainability debate. International Journal of Operations \& Production Management, 21(12), 1492-1502.

Yin, R. K. (2005) Estudo de caso: planejamento e métodos (3a ed.). Porto Alegre: Bookman.

Zanelli, J. C. (2002). Pesquisa qualitativa em estudos da gestão de pessoas. Estudos da Psicologia, 7, 79-88. 